\title{
ADOLESCÊNCIA EM MEMES: análise das representações de alunos do ensino fundamental
}

\author{
Judith Bustamante Bautista ${ }^{1}$ \\ Diana Ciannella ${ }^{2}$ \\ Miriam Struchiner ${ }^{3}$
}

\begin{abstract}
RESUMO
A multimodalidade evidenciada pelas Tecnologias Digitais de Informação e Comunicação impacta os adolescentes imersos na cultura digital. Contudo, práticas sociais e pedagógicas se distanciam, pois a escola ainda é regida por um sistema que não contempla questões do cotidiano do aluno, nem sua inserção na cibercultura. O objetivo do estudo é analisar como alunos do ensino fundamental representam sua fase de adolescência por meio da linguagem dos memes, os significados que emergem dessas representações e discutir suas implicações pedagógicas com base na Semiótica Social. Foi desenvolvida uma oficina onde 19 alunos (13-15 anos) do $8^{\circ}$ ano do ensino fundamental da cidade do Rio de Janeiro produziram memes a partir do aplicativo Meme Generator. Os memes foram analisados à luz da Gramática do Design Visual, que apontou prevalência de processos narrativos reacionais $(n=17)$, cujas reações identificadas foram classificadas como: frustração $(n=5)$; dilema $(n=4)$; sarcasmo $(n=2)$; resistência $(n=2)$; baixa autoestima $(n=2)$ e satisfação $(n=1)$. Os demais memes $(n=2)$ utilizaram processo conceitual e processo narrativo acional. Os resultados apontaram marcas de aspectos socioculturais de contextos como escola, amigos, família e futuro, com indicativos de resistência a preconceitos, de dúvidas, conflitos, alegria com momentos de lazer e desejos. Destaca-se que as representações por meio dos memes ofereceram indícios de como esses jovens veem sua adolescência, além de evidenciar questões que permeiam o cotidiano de tais alunos. Dessa forma, os memes podem contribuir para a discussão e construção de um currículo multicultural.
\end{abstract}

Palavras-chave: Adolescência. Meme. Semiótica Social. Gramática do Design Visual. Práticas pedagógicas.

\section{ADOLESCENCE IN MEMES: analysis of elementary school student's}

\section{representations}

\footnotetext{
1 Mestre em Educação em Ciências e Saúde - Instituto Nutes/UFRJ. Orcid: https://orcid.org/0000-0003-4054-5083 E-mail: judbbautista@yahoo.com.br

2 Doutora em Educação em Ciências e Saúde. Técnica em Assuntos Educacionais - Instituto Nutes/UFRJ. Orcid: https://orcid.org/0000-0003-2468-5457 E-mail: diciannella@yahoo.com.br 3 Doutora em Educação - Boston Univerity. Professora Titular do Instituto Nutes/UFRJ. Orcid: https://orcid.org/0000-0002-9979-2364 E-mail: miriamstru@gmail.com
} 


\section{ABSTRACT}

The multimodality evidenced by Digital Information and Communication Technology impacts adolescents' lives immersed in digital culture. However, social and pedagogical practices are not integrated since school curriculum does not take into account students' experiences and knowledge based on their daily life, nor their intense engagement in cyberculture. The present study adopted the Social Semiotic approach to analyze how elementary school students use Memes to represent their adolescence, to evidence the meanings that emerged from these representations, and to discuss their pedagogical implications. A workshop was implemented with 19 8th grade elementary public school students (13-15 years old) in the city of Rio de Janeiro, when they have produced memes using Meme Generator application. The memes were analyzed in the light of The Grammar of Visual Design which pointed to the prevalence of reactive narrative processes $(n=17)$, classified as: frustration ( $n=$ $5)$; dilemma $(n=4)$; sarcasm $(n=2)$; resistance $(n=2)$; low self-esteem $(n=2)$, and satisfaction $(n=1)$. The other memes $(n=2)$ expressed conceptual and action narrative processes. Students' representations emphasized the sociocultural aspects of their living contexts such as school, friends, family, and future, indicating resistance to prejudice, doubts, conflicts, joy with leisure moments, and desires. It's noteworthy that the representations through memes offered signs of how these young people see their adolescence, in addition to highlight issues that permeate the daily lives of these students. In this way, memes can contribute to the discussion of a multicultural curriculum.

Keywords: Adolescence; Meme; Social Semiotics; The Grammar of Visual Design; Educational practices.

\section{ADOLESCENCIA EN MEMES: análisis de las representaciones de alumnos de nivel básico}

\section{RESUMEN}

La multimodalidad evidenciada por las Tecnologías Digitales de Información y Comunicación impacta a los adolescentes inmersos en la cultura digital. Sin embargo, prácticas sociales y pedagógicas se alejan, pues la escuela todavia es guiada por un sistema que no abarca cuestiones del cotidiano del alumno, tampoco su conexión con la era digital. El objetivo deste estudio es analisar como los alumnos del nivel básico representan la etapa de su adolescencia por medio del lenguaje de los memes, los significados producidos en las representaciones y discutir sus implicaciones pedagógicas bajo el enfoque de la Semiótica Social. Por lo tanto, se desarrolló un taller en el cual 19 alumnos (13-15 años) del nivel básico, de la ciudad de Rio de Janeiro, produjeron memes por medio del aplicativo Meme Generator. Los memes se analisaron a la luz de la Gramática Visual, donde resultaron procesos narrativos de reacción $(n=17)$, los cuales se clasificaron como: frustración $(n=5)$; dilema $(n=4)$; sarcasmo $(n=2)$; resistencia $(n=2)$; baja autoestima $(n=2)$ y satisfacción $(n=1)$. Los demás memes $(n=2)$ utilizaron proceso conceptual y proceso narrativo de acción. Los resultados senãlaron matices socioculturales de contextos tales como escuela, amigos, familia y futuro, con indicativos de resistencia a los prejuicios, dudas, conflictos y alegria. Cabe destacar que las representaciones por médio de los memes ofrecieron indícios sobre como estos jóvenes ven sua adolescência, además de evidenciar cuestiones que están alrededor del cotidiano de estos alunos. Por tanto, los memes pueden contribuir a la discusión y construcción de um currículo multicultural. 
Palabras clave: Adolescencia. Meme. Semiótica Social. Gramática Visual. Prácticas pedagógicas.

\section{INTRODUÇÃO}

A convergência de mídias digitais favorece novas formas de pensar, agir e se comunicar, influenciando o processo de construção, apropriação e disseminação de significados, além da reconfiguração das práticas sociais de linguagem (KRESS, 2003; ZACHARIAS, 2016).

Segundo Jenkins (2009), parte expressiva do público que acessa a web cria ou consome produções no contexto da perspectiva multimodal, integrando modos semióticos como imagem, texto, áudio e vídeo, para propagar conceitos, preconceitos, críticas e brincadeiras. Os jovens em idade escolar representam uma parte desse grupo e, por isso, argumenta-se que a escola deva estar em consonância com o desenvolvimento de conhecimentos e habilidades inerentes à cultura digital de seus alunos. Nesse sentido, discute-se a incorporação dos conhecimentos e recursos digitais à prática pedagógica para favorecer o processo de ensino-aprendizagem (ZACHARIAS, 2016). Esses jovens crescem habituados aos ritmos acelerados das tecnologias, porém são submetidos a um modelo escolar que, em grande parte, ainda não se apropriou pedagogicamente dessas ferramentas digitais (KENSKI, 2012).

Almeida e Valente (2012) alertam para a necessidade de se compreender e apropriar das Tecnologias Digitais de Informação e Comunicação (TDIC), como "linguagens que estruturam os modos de pensar, fazer, comunicar, estabelecer relações com o mundo e representar o conhecimento" (p. 61). Para Almeida (2016), independentemente de a escola adotar artefatos tecnológicos, esses já convivem no ambiente escolar, trazidos pela mão do aluno, como celulares, ou mesmo pelo seu próprio modo de pensar e agir, construído pela sua participação na cultura digital. Assim, embora eventualmente as tecnologias não estejam presentes fisicamente na escola, elas demandam ressignificações das práticas educativas. Um artefato de grande popularidade, e que vem sendo discutido por pesquisadores como 
um potencial recurso pedagógico, é o meme. Nesta perspectiva, o meme pode contribuir para auxiliar o desenvolvimento de habilidades de leitura, escrita e interpretação, durante situações em que o indivíduo analisa a representação de cada meme, ou quando o produz, (re)criando assim seus próprios argumentos e discursos interpretativos. Ademais, a partir do meme, o sujeito aufere a oportunidade de conhecer e participar de discussões oriundas de contextos que não necessariamente constituem parte de seu universo cultural, o que se configura como uma experiência de aprendizagem (COELHO, 2017; OLIVEIRA; PORTO; ALVES, 2019).

Ao considerar que um meme é produzido com a finalidade de comunicar uma mensagem curta, seja em tom crítico ou bem-humorado, pode-se compreendê-lo como um gênero textual, que ganha grande alcance ao ser compartilhado nas redes do ciberespaço, entrelaçando-se a outros. Almeida e Valente (2012), ao discutirem a contribuição das TDIC à educação, na perspectiva de integração das linguagens midiáticas e currículo, destacam as narrativas produzidas por meio das TDIC como uma forma de construção e representação de conhecimento. Segundo esses autores, professores podem identificar com o currículo os conhecimentos de seus alunos e as relações que estão sendo capazes de tecer, a partir da análise de narrativas digitais produzidas pelos alunos. Dessa forma, podem auxiliar pedagogicamente nos aspectos em que os alunos ainda apresentam dificuldades, ajudando-os de modo mais efetivo, no desenvolvimento do processo de aprendizagem. Assim, as narrativas podem ser concebidas como "janelas na mente" dos alunos, que potencialmente facilitem o desenvolvimento do processo de ensinoaprendizagem, ao mesmo tempo em que aproximam a prática pedagógica da cultura digital e seus artefatos (ALMEIDA; VALENTE, 2012, p. 73). É nesse sentido que o meme pode ser compreendido como uma narrativa digital, passível de ser pedagogicamente integrado ao processo de ensino-aprendizagem.

No atual cenário social cada vez mais tecnológico, se acentua a defasagem entre o currículo e a diversidade do universo sociocultural dos alunos (CANEN, 2007; CANDAU, 2008; KENSKI, 2012). Assim, pode-se supor que as competências dos adolescentes, nas suas diversas formas de letramento, bem 
como as múltiplas dimensões que compõem a vida para além da escola, tais como família, mídia, cultura e aspectos biológicos relativos à puberdade, não estão sendo valorizadas na escola. Camacho (2004) argumenta que os debates entre pesquisadores se concentram na fragmentação do trabalho docente e pouco questionam a visão fragmentada do estudante, uma vez que a escola, especialmente no ensino fundamental, concebe o aluno como criança ou apenas como aluno, mas raramente como jovem. Assim, a autora defende que a visibilidade das juventudes, com suas especificidades, depende de propostas pedagógicas que valorizem a condição de jovem, o que precede à condição de aluno, sendo ambas intimamente ligadas. Ademais, é necessário romper com a visão negativa dos jovens como indivíduos problemáticos, para aproximar o currículo das suas experiências, valorizando o protagonismo juvenil por meio de projetos que consideram seus interesses (PÁTARO; MORUZZI, 2011).

Assim, neste cenário de distanciamento entre o currículo escolar e os saberes cotidianos dos alunos, construídos pela sua participação em outros espaços e na cultura digital, observa-se como consequência o desinteresse dos alunos pela escola. Portanto, é preciso pensar em como motivá-los e promover a integração entre os conteúdos escolares e as realidades dos estudantes, de modo que o processo de aprendizagem seja mais significativo para tais alunos. Nesse sentido, o presente estudo objetivou analisar como alunos do ensino fundamental representam sua fase de adolescência, por meio da linguagem de memes, e que significados emergem a partir dessas representações. Ademais, discutir os potenciais pedagógicos dos memes e das questões de adolescência para a construção de um currículo multicultural com estratégias de ensino que aproximem a escola das realidades de seus alunos.

\section{FUNDAMENTAÇÃO TEÓRICA}

De acordo com Bock (2007), o conceito de adolescência relaciona-se à fase da transição da infância para a vida adulta, cujo processo é uma construção social de cada cultura. Já o termo puberdade, muitas vezes 
empregado como sinônimo de adolescência no senso comum, refere-se aos fenômenos fisiológicos e anatômicos do corpo, considerados como mudanças universais (WORTHMAN; TRANG, 2018). Nesse sentido, esclarece-se que a puberdade faz parte da adolescência. Assim, os adolescentes atravessam uma fase de transformações em sua vida, ao mesmo tempo em que ocorrem mudanças sociais e desafios globais, potencializados pelas inovações tecnológicas da era digital (DAHL et al, 2018).

Dahl et al (2018) destacam que os adolescentes têm sido especialmente impactados pelas transformações culturais e sociais geradas pelas tecnologias, uma vez que eles costumam ser os primeiros usuários das inovações. Segundo os autores, isso pode indicar que tais jovens estão vulneráveis a riscos inerentes ao ciberespaço, mas as tecnologias também podem trazer importantes oportunidades de aprendizagem e interações sociais.

A geração atual de crianças e jovens tem se beneficiado pelo anonimato das mídias digitais no sentido de uma maior participação horizontal (KENSKI, 2012), dado que considerável parcela das informações disponíveis na rede é pública. Esse tipo de interação favorece a expressão de ideias e o compartilhamento de narrativas digitais (MANOVICH, 2005).

A narrativa é compreendida como uma prática universal e "transhistórica e transcultural", que atravessa tempos e sociedades, espelhando suas ações e estruturas (BARTHES, 1971, p.19). Com o avanço das TDIC, Ferrari (2007) atualiza esse conceito e afirma que a sociedade contemporânea também se estrutura em torno das histórias que o ser humano expõe na web e da sua intensa necessidade de trocar informações de forma imediata, o que potencializa a disseminação de narrativas.

Assim, percebe-se que as TDIC estão modificando o ambiente social, ao permitir a caracterização de novas práticas sociais e culturais como as novas linguagens para representar experiências (ALMEIDA; VALENTE, 2012). Nessa perspectiva, o meme se configura como uma importante linguagem da cultura digital, usada com frequência para narrar fatos do cotidiano.

O termo meme foi cunhado por Dawkins (1976), que fez uma analogia com o gene, transmissor de informações genéticas, em correspondência à 
transmissão cultural promovida pelos memes. Para Blackmore (1999), os memes são fragmentos de experiências presentes em nossa memória e, portanto, não são vistos como uma inovação da cultura digital, mas como um artefato ressignificado pelo homem no contexto contemporâneo. Milner (2012) explica que a transformação de conteúdo que ocorre nos memes caracteriza uma relação de aderência às questões sociais, ocorrendo como uma manifestação de cultura participativa e criativa, seja para fazer humor, criticar, argumentar etc. Portanto, a intertextualidade é uma característica marcante do meme digital, concebida a cada releitura, a partir de distintos contextos, tais como filmes, política, música, notícias e demais situações cotidianas locais ou globais (NISSEMBAUM; SHIFMAN, 2017).

Ao criar memes, os sujeitos podem mesclar a linguagem verbal e a visual, com diversos recursos semióticos, mobilizar conhecimentos, inferências e relações intertextuais, além de desenvolver habilidades relacionadas aos multiletramentos (FERREIRA; VILLARTA-NEDER; COE, 2019). Segundo Rojo (2012), os multiletramentos se caracterizam pela interatividade e quebra de relações de poder, por meio de visão inclusiva.

$\mathrm{Na}$ esfera educacional, Rojo (2012) defende uma pedagogia de multiletramentos, que leva em consideração a multiplicidade de linguagens e culturas. Cope e Kalantzis (2009) também destacam que esse olhar abarca todas as formas de representação, ao valorizar o processo de construção de conhecimento e não apenas a mera reprodução de conteúdo. Nesse sentido, compreende-se o meme como uma construção que se origina dos letramentos dos sujeitos e, por isso, é considerado como um dispositivo auxiliar ao desenvolvimento da aprendizagem e difusor de significados (COELHO, 2017). Portanto, o meme, inserido em uma estratégia educativa baseada na pedagogia dos multiletramentos, envolve a diversidade cultural e a multiplicidade de canais de comunicação e mídias, que permeiam a atual sociedade na qual os jovens estão inseridos (ROJO, 2012).

Uma perspectiva que considera as interações multimodais é a Semiótica Social, que estuda os signos sociais (HODGE; KRESS, 1988) e valoriza as construções de significados por vários modos semióticos, com base nos 
interesses do produtor, quem concebe o significado, e na interação social. Dessa maneira, a Semiótica Social retrata como premissa o reconhecimento da dimensão social, para compreender a estrutura e o processo da linguagem e, por isso, nenhum modo semiótico pode ser estudado de forma isolada do contexto social em que está inserido (HODGE; KRESS, 1988).

Associada à Semiótica Social, a Gramática do Design Visual (GDV) é uma lente para analisar modos de representação e refletir acerca dos processos sociais e culturais envolvidos nas representações (KRESS; VAN LEEUWEN, 2006). Kress (2010) definiu representação como o interesse de um indivíduo na sua relação com o mundo e na pretensão em materializar os significados acerca do mundo. Assim, a Semiótica Social, ao entender as construções de significados com base nas interações sociais, pode auxiliar a compreensão dos memes ao mesmo tempo em que valoriza a autoria e a diversidade cultural.

No presente estudo, a Semiótica Social e a GDV foram adotadas como referenciais de análise das produções de memes dos estudantes, para investigar os significados expressos sobre sua própria adolescência. O meme é um artefato multimodal presente no cotidiano da internet e adotado pelos jovens para construir representações sobre os mais diversos temas de sua vida. As especificidades técnicas da GDV, que permitiram explorar os significados dessas representações, são explicitadas na seção seguinte.

\section{METODOLOGIA}

Trata-se de uma pesquisa qualitativa (MINAYO, 2002), tendo em vista que seu objetivo foi analisar, na perspectiva da Semiótica Social e da GDV, as formas de expressão e significados construídos pelos alunos em uma oficina pedagógica. Do ponto de vista da coleta de dados, trata-se de uma pesquisa participante (LE BOTERF, 1999), uma vez que os pesquisadores envolveram-se na ação com os sujeitos, não apenas como observadores.

As etapas da pesquisa foram as seguintes: (1) estabelecimento de parceria com a coordenadora pedagógica e professores; (2) planejamento e implementação da atividade pedagógica - "Oficina Multiletramentos: 
expressões e conhecimentos dos jovens na cultura digital"; (3) análise dos memes produzidos na última fase da oficina.

\section{Contexto e sujeitos da pesquisa}

Esta pesquisa foi realizada em uma escola pública da zona norte do Município do Rio de Janeiro, que atende cerca de 350 alunos, do $6^{\circ}$ ao $9^{\circ}$ ano do ensino fundamental II, provenientes de classe média baixa.

Participaram do estudo 19 alunos (13-15 anos) do $8^{\circ}$ ano. Essa turma foi selecionada em parceria com a coordenadora pedagógica e os professores de Ciências e Português, os quais destacaram que, além de o currículo de Ciências abordar temas relacionados ao corpo, puberdade e adolescência, os alunos do $8^{\circ}$ ano também apresentavam dificuldades com suas atividades de escrita.

\section{Procedimentos para a coleta e análise de dados}

Os procedimentos para coleta e análise de dados foram: (1) realização da atividade pedagógica com a turma; (2) descrição e análise de cada meme segundo a GDV e (3) discussão dos significados das representações e suas implicações pedagógicas para o currículo escolar.

Com base na Semiótica Social (HODGE; KRESS, 1988) e nos multiletramentos (ROJO, 2012), foi desenvolvida a "Oficina Multiletramentos: expressões e conhecimentos dos jovens na cultura digital", organizada em duas fases. Na primeira, os alunos foram estimulados a responder questões motivadoras referentes às diversas dimensões que influenciam a adolescência, tais como biológica, social, cultural e psicológica, ou seja, seu universo bio-psicosociocultural. As respostas foram construídas a partir do uso de diferentes recursos (podcasts, gifs, memes, histórias em quadrinhos, editor de texto). Na segunda fase, os alunos trabalharam com a estação meme', que teve como como foco a representação da adolescência a partir de uma pergunta. A opção por esse recurso foi definida a partir da observação, realizada na primeira fase, quanto ao

\footnotetext{
${ }^{4}$ Nome dado a cada mesa pela qual os alunos tinham que passar e usar algum recurso: estação meme, estação histórias em quadrinhos etc.
} 
interesse e familiaridade dos alunos face aos equipamentos como notebooks, tablets/ipad e celulares com acesso à internet, quanto à facilidade de uso do aplicativo Meme Generator e à viabilidade das condições operacionais em sala de aula. A questão motivadora colocada para os alunos produzirem os memes foi: "E você, como representa este momento de transição?". Essa pergunta foi proposta após a apresentação de memes de um dos pesquisadores sobre seu momento de transição na vida, aos 64 anos, fazendo referência a diferentes aspectos bio-psico-socioculturais. A ideia foi sensibilizar os alunos para o fato de a vida revelar seus momentos de mudanças e mostrar exemplos de representações, em memes, que ajudariam a refletir e expressar seu contínuo processo de transição, como a adolescência.

Dos 33 alunos participantes da oficina, 19 entregaram termo de assentimento de seus responsáveis, para análise de seus memes nesta pesquisa. Os alunos foram identificados, iniciando de Al até A19, e suas produções de M1 a M19. A realização da oficina ocorreu no turno habitual de aula da turma com a presença dos professores.

Esta pesquisa foi aprovada pelo Comitê de Ética (CEP) institucional, sob o Parecer n. 3.127.572.

\section{Aporte metodológico de análise: Gramática do Design Visual}

Para analisar as formas de representação dos alunos sobre sua adolescência, adotou-se a teoria da Semiótica Social, a qual estuda a gênese do significado (HODGE; KRESS, 1988) e utiliza a GDV como ferramenta de análise (KRESS; VAN LEEUWEN, 2006). A GDV se concentra no nível estrutural da imagem, levando em conta três tipos de perspectivas, que coexistem e contribuem na composição do significado: metafunção representacional, interacional e composicional. Essas metafunções permitem a interpretação dos elementos visuais presentes em distintos modos semióticos, a partir da relação da imagem, produzida pelo autor, com o leitor (KRESS; VAN LEEUWEN, 2006). 
A metafunção representacional permite identificar e caracterizar ações e relações entre sujeitos e/ou elementos, também denominados de participantes e representados por PR na imagem. Essa metafunção apresenta dois tipos de processos: narrativo e conceitual. No processo narrativo, observam-se ações ou reações entre os sujeitos e/ou elementos e, por isso, é subdividido em acional e reacional, respectivamente. No processo conceitual, os sujeitos e/ou elementos da imagem estão estáticos, não esboçam qualquer ato (JEWITT; OYAMA, 2001).

A metafunção interacional possibilita perceber a interação estabelecida entre o elemento que representa o autor na imagem (PR) e o seu leitor, também chamado de participante interativo (PI). Essa interação consiste nas seguintes categorias: contato, distância social, perspectiva. A categoria contato diz respeito à interação entre elemento representado e PI por meio do olhar. Quando PR está com o olhar voltado para outro elemento, presente ou não na imagem, entende-se que não há interação visual com Pl e, nesse caso, diz-se que o contato de PR com PI se dá por "oferta". Nesse tipo de contato, PR é visto pelo observador como um objeto de contemplação, que apenas informa algo ao leitor (KRESS; VAN LEEUWEN, 2006). Se houver uma interação visual direta, em que PR tenha o olhar voltado para a direção do leitor (PI), diz-se que o contato ocorre por "demanda". Isso significa que o autor da imagem está demandando que o leitor tome uma atitude ou se sensibilize. A análise referente a "distância" entre PR e PI é definida por meio do enquadramento da imagem de PR, que pode ser de três tipos: plano fechado, plano aberto e plano médio. No plano fechado, apenas parte de PR é focalizada de modo ampliado, evidenciando algum detalhe ou expressão facial, por exemplo, quando somente a face de PR está evidente, ocupando grande espaço da imagem. Esse plano costuma ser usado para que o leitor sinta uma relação próxima, pessoal, com o tema que está sendo abordado na imagem e possa até engajar-se na causa em questão. O plano aberto, em contraposição ao fechado, oferece visão completa de PR, por exemplo, quando o elemento PR aparece na íntegra na imagem, indicando uma distância impessoal, uma relação pouco estreita entre PR e PI. O plano médio é aquele que focaliza parte de PR, tal como quando PR aparece na imagem apenas da cintura para cima, estabelecendo uma distância 
intermediária entre PR e PI. Nesse plano, a situação representada pode até ser conhecida pelo leitor, mas não Ihe desperta intimidade.

O mesmo modo semiótico ainda pode ser analisado em relação à perspectiva, que diz respeito ao "ponto de vista" ou ângulo a partir do qual PR é representado para o leitor. A observação de PR ocorre a partir de dois eixos de perspectiva, horizontal ou vertical, os quais caracterizam relações de envolvimento ou poder entre PR e PI, respectivamente. Na perspectiva horizontal, PR pode ser apresentado a PI por dois tipos de ângulo: frontal ou oblíquo. O uso do ângulo frontal ocorre quando PR posiciona-se de frente para Pl, que é chamado a envolver-se na situação de PR, como algo que Ihe diz respeito e que faz parte do seu mundo. Ao utilizar o ângulo oblíquo, PR encontra-se de lado ou de costas, o que mostra distanciamento entre PR e Pl, indicando que ambos não têm nada a compartilhar, pois PR não pertence ao mundo de PI. Na perspectiva vertical, PR pode ser apresentado a Pl a partir de três ângulos: alto, baixo ou ao nível do olhar. O ângulo alto caracteriza-se quando PR está posicionado na região inferior da imagem e, por isso, PI o observa de cima para baixo, o que indica que há uma relação de submissão de PR quanto a PI. O ângulo baixo caracteriza-se quando PR está posicionado na região superior da imagem e, por isso, $\mathrm{Pl}$ o observa de baixo para cima, o que indica uma relação de domínio de PR sobre PI. Quando PR está posicionado em ângulo ao nível do olhar de Pl, ocorre uma relação de igualdade entre eles (KRESS; VAN LEEUWEN, 2006).

A metafunção composicional compreende a distribuição espacial dos elementos, inclusive a parte textual, atribuindo coerência visual à produção e relevância à informação. Essa metafunção permite perceber a forma como os elementos da imagem se organizam para compor um significado maior, com base em três planos de análise: valor de informação, saliência e estruturação. No plano de análise "valor de informação", verifica-se a localização dos elementos: topo/base, esquerda/direita e centro/margem. O elemento no topo da imagem transmite um significado de algo ideal, e aquele localizado na base expressa um significado de algo real. Quando situado ao lado esquerdo, considera-se que a informação é dada, como 
algo conhecido pelo senso comum. Se estiver ao lado direito, a informação é nova, o que significa romper com o convencional. No plano de análise "saliência", verifica-se a maior ou menor ênfase dada pelo autor ao usar contrastes de cores e tamanhos dos elementos. No plano de análise de "estruturação", é possível identificar se os elementos estão conectados ou não entre si por meio da presença ou ausência de linhas estruturantes, indicando como o autor deseja que os elementos e a informação transmitida por eles sejam compreendidos pelo leitor. Essas linhas podem ser visíveis na imagem ou não, podendo ser percebidas pelo leitor de acordo com a disposição dos elementos na imagem. Assim, os participantes são considerados como mais estruturados quando estiverem separados por linhas e, portanto, desempenhando papéis individuais, ou menos estruturados quando não houver linhas separando-os, o que configura um coletivo (KRESS; VAN LEEUWEN, 2006).

Dessa maneira, o autor, também denominado designer por Kress (2003), escolhe recursos semióticos que possam produzir o significado que ele deseja transmitir ao leitor, sendo sua construção influenciada ao mesmo tempo por suas experiências pessoais, bem como pelas transformações sociais e tecnológicas (DAHL et al, 2018). As metafunções ocorrem simultaneamente ao construir significados motivados, por meio de seus recursos semióticos. Com base nessas metafunções, as representações dos alunos foram analisadas e interpretadas.

\section{ANÁLISE DAS REPRESENTAÇÕES DE ADOLESCÊNCIA DE ALUNOS EM MEMES}

Os memes produzidos (Figura 1) pelos 19 alunos foram analisados segundo a GDV (KRESS; VAN LEEUWEN, 2006).

Os alunos, em sua maioria ( $n=18)$, utilizaram o banco de imagens do software Meme Generator para criar seus memes. Apenas um aluno importou uma imagem do Google para compor seu meme no mesmo software. Entre os 19 memes, 11 apresentaram imagens distintas. Dois alunos selecionaram a mesma imagem do personagem de desenho animado Bob 
Esponja (M12 e M13), dois preferiram uma imagem conhecida na Internet como "Namorado Distraído" (M5 e M10) e quatro optaram pela mesma imagem do personagem Homem de Ferro (M8, M14, M17 e M18). Além do Homem de Ferro, outros personagens de filmes também foram selecionados, como o Homem Aranha (M6), e os dos filmes "Os bons companheiros" (M3), "Sexta-feira em apuros" (M7) e "Como enlouquecer o seu chefe" (M11). Os alunos também escolheram um participante do reality show Jersey Shore, transmitido por um canal de TV (MTV), conhecido como DJ Pauly (M16) e uma modelo e integrante do reality show da família Kardashian, Kendall Jenner (M9); integrantes do grupo musical coreano BTS (M1) e um personagem dos quadrinhos de Jake Clarck (M3). As demais imagens referem-se às cenas cotidianas de pessoas anônimas que ganharam popularidade, tornando-se memes conhecidos como "Bebê Sucesso" (M2), "Namorado Distraído" (M5 e M10), "Confissão de Criança" (M19) e "Mulher Presidiária" (M15).

FIGURA 1 - Memes de alunos elaborados em uma oficina pedagógica para representar a adolescência

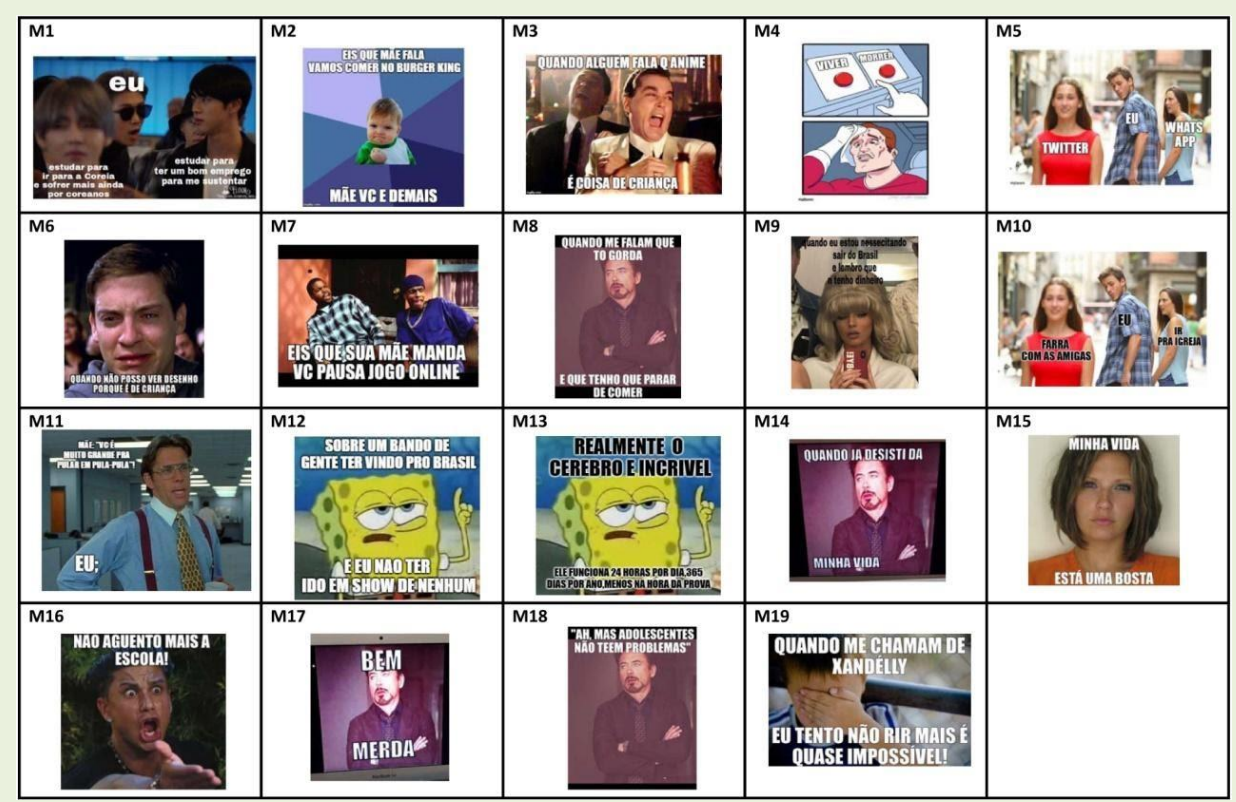

Fonte: Produção dos alunos do $8^{\circ}$ ano do ensino fundamental.

A análise e interpretação dos memes ocorreram a partir dos seguintes aspectos: descrição geral do meme, origem/contexto da imagem e aspectos específicos das metafunções representacional, interacional e composicional. 
Do ponto de vista da GDV (KRESS; VAN LEEUWEN, 2006), na metafunção representacional identificaram-se os seguintes processos: Processo Narrativo Reacional ( $n=17)$; Processo Narrativo Acional $(n=1)$ e Processo Conceitual $(n=1)$.

Dessa maneira, o processo narrativo prevaleceu entre os memes analisados, o que revela a preferência dos alunos em representarem a adolescência por meio de reações entre os sujeitos e/ou elementos representados e não por conceitos. Isso significa que os memes mostram personagens reagindo a algo ou praticando alguma ação, tendo alguma interação com o leitor. Por outro lado, o processo conceitual foi encontrado em apenas um meme (M15), sendo utilizada a imagem de uma mulher que não esboça nenhuma ação (figura 1).

Em relação à metafunção interacional, os personagens selecionados estavam, em sua maioria, em posição de oferta $(n=17)$, em plano médio $(n=10)$ e plano fechado $(n=9)$, o que indica maior visibilidade dos personagens devido ao enquadramento, que destaca as expressões faciais, demandando assim maior atenção do leitor. Sobre o plano horizontal, grande parte dos participantes representados se mostrou em posição oblíqua ( $n=17)$. Já no plano vertical, os ângulos ao nível do olhar $(n=8)$ e alto $(n=8)$ se mostraram equilibrados, enquanto o ângulo baixo não foi muito utilizado (n=3). Esse resultado mostra que os alunos se representaram predominantemente de forma igualitária ou superior em relação ao leitor dos memes, com o olhar de seus personagens no mesmo nível ou acima do olhar do leitor. Isso indica que esses adolescentes não se colocaram em posição submissa com suas questões em relação ao leitor, o que sugere uma autoconfiança.

Quanto à metafunção composicional, os recursos mais utilizados foram a centralização dos participantes representados e o espaço superior e inferior. Apenas M1, M3, M5, M7 e M10 utilizaram mais de um personagem, entre os quais três (M1, M5 e M10) apresentaram participantes secundários que estavam representando questões relacionadas ao participante principal. A centralização dos participantes também foi evidenciada pelo plano fechado da metafunção interacional, dando visibilidade tanto ao 
processo narrativo quanto ao conceitual. Isso indica que a maioria dos alunos utilizou recursos que aproximaram o leitor dos personagens selecionados para representá-los. Assim, a partir da leitura dos memes pela ótica da GDV (KRESS; VAN LEEWUEN, 2006), foi possível perceber indícios de questões relativas à adolescência.

Dessa maneira, as produções reuniram imagens e configurações próprias do gênero meme para representar as visões de adolescência, utilizando os recursos do espaço visual segundo as três metafunções da GDV, assim como construções verbais próprias de memes que circulam na web, como "QUANDO..." (M3, M6, M8, M9, M14, M19) e "EIS QUE..." (M2 e M7). Todos esses pontos situam os memes como dispositivos de linguagem que, nesse caso, podem mostrar indícios da fase da adolescência, assim como aspectos culturais e sociais vivenciados por seus autores (SHIFMAN, 2014).

A partir dos dados identificados com a GDV, foi possível compreender os significados dos memes e constatar que a maioria dos alunos $(n=17)$ criou memes cujos participantes representados revelaram distintas reações, organizadas em seis grupos. A reação denominada frustração (M6, M7, M9, M11, M12 e M16) reúne memes com sentidos de contrariedade, nos quais os autores representaram situações contrárias à sua vontade. A reação denominada dilema (M1, M4, M5 e M10) agrupa aqueles que representaram reações a duas situações. A reação denominada sarcasmo (M3 e M13) reúne memes compostos de riso e crítica perante as situações em que se encontram. A reação de resistência (M8 e M18) está relacionada à negação de padrões sociais. A reação de baixa autoestima (M14 e M17) foi percebida em memes que demonstraram baixas expectativas em relação à vida ou ao futuro. A reação de satisfação (M2) apresenta alegria, identificada em um único meme. Apenas dois memes não apresentaram personagens com reações, mas em posição estática (M15) e em ação de cobrir o rosto (M19), diferenciando-se dos memes nos grupos de reação.

A reação de frustração foi recorrente entre os memes $(n=6)$. Os memes M6 (desejo de assistir desenho animado), M7 (desejo de continuar jogando jogos on-line) e M11 (desejo de brincar no pula-pula) apontam reações 
relacionadas à dicotomia entre desenvolvimento físico e amadurecimento, pois expressam vontade de realizar atividades consideradas como infantis por pais e outros adultos. Os memes M9 (desejo de sair do Brasil), M12 (desejo de ir a shows internacionais) e M16 (desejo de não ir à escola) expressam reações relacionadas à falta de autonomia para tomar decisões. Essas reações mostram que os autores de tais memes representaram situações adversas entre os seus desejos e as expectativas sociais dos adultos. Desse modo, por estarem em uma fase de transição entre a infância e a vida adulta, os adolescentes estão sujeitos a impasses em que ora são tratados como adultos, ora como crianças (COUTINHO, 2009). Portanto, são cobrados a ter comportamentos e atitudes adultas, pois biologicamente são considerados "maduros", especialmente por seus familiares. Ao mesmo tempo, não têm autonomia para realizar todos os seus desejos, por serem considerados imaturos e jovens demais para certas atividades ou decisões, além de dependerem financeiramente de seus responsáveis.

A reação de dilema reuniu memes com distintas dúvidas, as quais expressaram dilemas voltados para aspectos sociais, emocionais e expectativas do futuro. Os memes M5 e M10 apresentam dilemas sociais, pois ambos ressaltam as possibilidades de escolha entre diferentes redes sociais, como Twitter e WhatsApp (M5) e grupos de amigos ou igreja (M10). O meme M4 apresenta um dilema que parece estar relacionado a algum conflito pessoal, pois o aluno mostra uma imagem de um personagem aparentemente nervoso ou preocupado por ter que escolher entre dois botões, aos quais o aluno atribuiu as opções viver ou morrer. Diferentemente, M1 expressa um dilema relacionado ao futuro, mostrando a dúvida entre a realização de um sonho e a realização de um dever, representada pelas opções de viajar e estudar em outro país e estudar para ter um emprego e se sustentar, respectivamente. Nesses quatro memes, cada aluno manifestou um dilema de acordo com seu contexto; alguns, com mais intensidade. Contudo, todos trazem questões que marcam a sua adolescência e evidenciam o que consideram importante, como sair com amigos, participar de redes sociais, conhecer outras culturas e ter autonomia. Conforme Dayrell (2007) e Dahl et al 
(2018), mesmo influenciados por valores familiares e culturais, adolescentes costumam buscar seu espaço de identificação ao longo do processo de amadurecimento e construção dos próprios valores. Além disso, o fator oscilação hormonal também pode influenciar situações de dilemas, especialmente relacionados aos aspectos emocionais, de forma intensa, como visto em M4 (WORTHMAN; TRANG, 2018). Nesse sentido, Dahl et al (2018) argumentam que, embora não se saiba exatamente o papel que determinados hormônios desempenham, percebe-se sua interferência no período da puberdade.

Sob a reação de sarcasmo, reuniram-se dois memes. Em M13, o aluno associa uma piada à dificuldade em realizar uma avaliação escolar e com o fato de o cérebro não funcionar conforme o esperado. Já em M3, a representação mostra um personagem rindo ao ser questionado sobre o fato de ter crescido e ainda assistir desenho. Assim, apesar de esses alunos usarem o humor para evidenciar essas questões, tais críticas parecem emergir de situações recorrentes que os incomodam, mostrando o quão importante são em sua vida. Destaca-se que M3 apresenta a mesma questão trazida por $M 6, M 7$ e $M 11$, relativa ao fato de não serem mais crianças para participar de atividades, como assistir desenhos, brincar em pula-pula ou jogar videogame, cujas práticas são consideradas infantis pelos adultos. Embora se observem divergências entre adultos e adolescentes, para Vasconcelos (2006), o lúdico não se restringe apenas às crianças, porquanto atravessa gerações, sendo importante para o desenvolvimento humano e para a educação, independentemente de faixa etária.

Os memes M8 e M18 foram classificados como reação de resistência, os quais expõem críticas sofridas em relação ao sobrepeso (M8) e à ideia de que adolescentes não possuem problemas (M18). Essas reações podem indicar que tais alunos resistem às regulações sociais sobre o corpo e aos preconceitos contra a vida dos adolescentes. Nesse contexto de rechaçamento, ambos autores escolheram a mesma imagem do personagem do filme "Homem de Ferro", porém utilizaram o comportamento de resistência, para abordar distintos temas. A relação com o estado nutricional é uma questão recorrente na mídia, seja pela perspectiva da 
saúde ou da estética. E a obesidade no Brasil, especialmente entre adolescentes, já é considerada um problema de saúde pública, além de outros distúrbios alimentares. O discurso do corpo ideal, ao ser imposto à sociedade, pode desencadear uma insatisfação com a própria imagem corporal associada a esses distúrbios (MARTINS et al, 2010). Embora M8 sugira que sua autora não se importa com comentários sobre seu peso, isso é uma questão importante e que precisa ser discutida na mídia, na escola, em casa etc., a fim de que esse tipo de bullying velado, que afeta muitos jovens, seja reconhecido e combatido, bem como o culto excessivo ao corpo ideal.

A questão de $M 18$, sobre a ideia de que o adolescente não possui problemas, pode relacionar-se a uma visão dos adultos que consideram os adolescentes mais próximos da infância que da fase adulta e, por isso, não precisam lidar com responsabilidades, tais como o trabalho e a família, vistos como problemas para adultos (COUTINHO, 2009). Isso mostra que há níveis de importância das preocupações de adultos e de adolescentes, o que é refutado pela aluna autora de M18. Ao subestimar as dificuldades dos adolescentes, aumentam-se as chances de excluir questões que interferem nas relações sociais, na saúde e até no desempenho escolar (WORTHMAN; TRANG, 2018).

Na reação de baixa autoestima, os alunos utilizaram a imagem do personagem Homem de Ferro (M14 e M17). Embora tenham usado a mesma imagem de M8 e M18, os memes do primeiro grupo indicam baixa autoestima. Enquanto em M8 e M18 os alunos parecem ter uma postura de resistência contra preconceitos, os estudantes que elaboraram M14 e M17 apontam indícios de insatisfação em relação à sua adolescência, conforme sinalizam os textos: "QUANDO JÁ DESISTI DA MINHA VIDA" (M14); "BEM MERDA" (M17). Segundo Grolli, Wagner e Dalbosco (2017), não há dúvidas de que inúmeras transformações ocorrem nessa fase da vida, tanto em nível hormonal quanto neurológico, quando "o indivíduo passa por mudanças nas estruturas neuronais envolvidas com as emoções, o julgamento e o autocontrole, levando-o a processar as informações e emoções de forma diferente do adulto" (p.89). Diante dessa complexidade, percebe-se que os memes (M14; M17) mostram uma carga de significados relacionados à 
instabilidade emocional, o que pode afetar o desempenho escolar, os círculos sociais etc. Por isso, a visão ampliada da adolescência se faz necessária.

A reação de satisfação diz respeito à alegria observada em $M 2$, que representa a adolescência de forma positiva, com o convite de uma mãe para comer fast food, indicando uma atividade prazerosa. Este foi o único aluno que representou a sua adolescência sem algum questionamento ou conflito, valorizando o convívio familiar e a alimentação como uma atividade de lazer. Assim, a representação de adolescência em M2 é concebida mediante a relação afetiva com a mãe e a relação de consumo influenciada pela mídia, representada pelo fast food.

Diferentemente dos memes anteriores, M15 e M19 não apresentam participantes exercendo alguma reação. Em M19 foi identificado o processo narrativo acional para representar o constrangimento, quando faz brincadeira que associa o nome da aluna a uma marca de laticínio. Nesse caso, não há reação, apenas a ação do personagem de cobrir o rosto. Apesar dessa timidez sugerida pela imagem, o texto "QUANDO ME CHAMAM DE XANDÉLLY EU TENTO NÃO RIR MAIS É QUASE IMPOSSÍVEL!" expressa que a aluna ri da situação. Já M15 apresentou o processo conceitual para representar a sua adolescência, ao mostrar a imagem de uma mulher em posição estática. A imagem se origina de uma cena do cotidiano de uma mulher anônima dos EUA, presa por dirigir alcoolizada. A roupa que a mulher usa é de cor laranja, o que coincide com a cor de uniformes de presidiários americanos, conforme observado em filmes e seriados desse país. Isso pode ser um indicativo de que a autora desse meme o tenha escolhido para relacionar sua adolescência ao conceito de prisão, porém não se pode afirmar que ela conhecia o contexto de origem da imagem. Entretanto, a personagem mostra uma expressão indiferente, sem ação ou reação, e é acompanhada pelo texto "MINHA VIDA ESTÁ UMA BOSTA", o que pode representar um eventual indício de insatisfação dessa menina com algo em sua vida. 
No geral, os 19 alunos encontraram elementos de interesse do seu repertório cultural e representaram situações e sentimentos vinculados à sua fase de vida. Desse modo, as representações de adolescência foram construídas e baseadas nos temas: falta de autonomia; dicotomia entre desenvolvimento físico e amadurecimento; baixa autoestima; dilemas voltados para aspectos sociais, emocionais e para o futuro; resistência às regulações sociais e aos preconceitos; dificuldades em tarefas escolares; convívio familiar e alimentação como lazer.

Tais temas sugerem que esses jovens representaram a adolescência a partir de uma perspectiva mais crítica. Ao mesmo tempo em que deixam de ser crianças, precisam aprender a lidar com as expectativas e cobranças sociais em torno de si, expressando que a adolescência não se resume a uma simples passagem de fase. Assim, percebeu-se que as representações de adolescência apontaram aspectos socioculturais de suas realidades.

Alguns, como M14, que diz "Quando já desisti da minha vida", foram mais negativos quanto à percepção de sua adolescência. Grolli, Wagner e Dalbosco (2017) destacam que aspectos emocionais, que podem estar relacionados à baixa autoestima, como sugere a reação de $M 14$, influenciam o desempenho escolar dos adolescentes. Os autores defendem que a escola esteja atenta a esses sinais e promova ações que estabeleçam um ambiente motivador, acolhedor e saudável, de modo que contribuam para o bem-estar emocional de seus alunos e evitem o fracasso e abandono escolar, tendo em vista que esse momento é um período crítico para o aprendizado.

Destaca-se que aspectos relacionados às questões biológicas da adolescência, como as mudanças do corpo e a sexualidade, não foram mencionados. É importante considerar que essas questões ainda estão envoltas por muita discriminação e repressão na escola, o que pode ser 0 motivo da sua ausência nos memes. Conforme Furlanetto et al (2018), apesar de certos avanços, as práticas educativas relacionadas à sexualidade no Brasil ainda possuem caráter predominantemente preventivista, repressor e heteronormativo, o que ignora a constituição cultural, histórica e social da 
sexualidade e sua diversidade. Assim, é possível que os alunos não hajam se sentido à vontade para expor essa dimensão da adolescência.

\section{IMPLICAÇÕES PEDAGÓGICAS DAS REPRESENTAÇÕES DE ADOLESCÊNCIA E MEMES}

Os alunos abordaram distintas questões em suas representações da adolescência, as quais podem gerar importantes implicações pedagógicas, uma vez que a escola é um espaço comum de desenvolvimento, onde se encontram diversas culturas. Isso demanda uma visão multicultural e multirreferencial da educação, cujo currículo não pode ser estático, já que as práticas sociais estão em constante movimento: em sintonia ou em resistência às questões globais.

No entanto, o sistema educacional expressa bases ainda tradicionais. Pátaro e Moruzzi (2011) e Camacho (2004) argumentam que a escola e o currículo estruturam-se a partir de uma cultura adultocêntrica, que se distancia das culturas juvenis (PÁTARO; MORUZZI, 2011). Em sua pesquisa com professores do $7^{\circ}$ e $8^{\circ}$ ano do ensino fundamental, Camacho (2004) identificou que eles veem seus alunos adolescentes como sujeitos em transformação, difíceis, sem limites e sem identidade definida, por conta da própria fase de adolescência. Nesse sentido, tais professores convergem em um ponto de vista negativo sobre eles e desconhecem seus potenciais, interesses e subjetividades, inerentes às suas culturas juvenis. Camacho (2004) aponta que esses professores não compreendem quem são seus alunos e, por isso, não sabem lidar com eles. A autora destaca que:

A escola, ao não ter a capacidade de construir relações condizentes com as características, interesses, expectativas, linguagens dos seus jovens alunos, termina por criar rupturas, às vezes irreversíveis, entre o mundo escolar e o mundo juvenil do aluno. (CAMACHO, 2004, p. 338)

Dessa forma, Camacho (2004) defende que a escola deva perceber seus alunos como "jovens alunos", o que significa compreendê-los como jovens, antes de sua condição de alunos.

Nesse sentido, as representações de adolescência em memes pelos alunos do presente estudo podem contribuir para que suas visões, interesses, 
conflitos, sentimentos e percepções sobre suas vivências sejam compreendidos pelos professores. Tal reconhecimento é importante para que docentes e alunos possam estreitar suas relações e aprimorar as práticas escolares, de modo que essas integrem conhecimentos e experiências socioculturais desses adolescentes aos currículos, tornando-os mais significativos e motivadores para a aprendizagem. Diversas pesquisas corroboram e discutem a perspectiva de um currículo multicultural, que promova o diálogo entre a cultura de referência dos alunos e a cultura escolar, o que implica desconstruir um currículo adultocêntrico e monocultural (CORSI; LIMA, 2010).

Candau (2008) sinaliza que o distanciamento entre as experiências socioculturais dos alunos e a escola pode estar relacionado com sentimentos de baixa autoestima, elevados índices de fracasso e abandono escolar e com as frequentes manifestações de mal-estar e agressividade dos alunos em relação à escola e aos professores. Esse parece ser o caso evidenciado no meme M16, no qual o personagem demonstra uma reação de mal-estar e até agressividade em relação à escola, por meio da imagem de um homem gritando "NÃO AGUENTO MAIS A ESCOLA!". Compreende-se que a rotina escolar parece ser algo que incomoda esse aluno, porém o motivo não é explicitado. O autor do meme M13 também menciona uma dificuldade em relação à escola; no caso, às avaliações escolares, quando coloca um personagem comentando: "REALMENTE O CÉREBRO É INCRÍVEL. ELE FUNCIONA 24 HORAS POR DIA, 365 DIAS POR ANO, MENOS NA HORA DA PROVA". Assim, esse aluno explicita sua dificuldade em se adequar e corresponder às exigências dos modelos de avaliação da escola. É possivel que tal escola siga um modelo de ensino e avaliação tradicional, o qual prioriza a memorização de conteúdos. Se esses conteúdos não se relacionam com a vida do estudante e ele não entende sua importância, a tarefa de aprendê-los e memorizá-los pode ser, de fato, árdua e desanimadora.

Moreira e Candau (2003) já alertavam que a construção de um currículo com práticas pedagógicas multiculturais não é simples. Exige mudanças de objetivos, conteúdos, estratégias, avaliação e posturas dos 
educadores durante o processo educativo e não apenas a introdução pontual de determinadas práticas, temas, autores, celebrações, entre outros. Para isso, é preciso questionar as interpretações hegemônicas da nossa cultura, debater as relações entre os diferentes grupos sociais e étnicos e reconhecer a cultura da comunidade, onde a escola se insere. Tal perspectiva nem sempre é compreendida, ou vista como possível pelos professores, devido às dificuldades cotidianas relacionadas à infraestrutura, carga horária, cobrança por índices de avaliação externa, além da própria formação que, em muitos casos, ainda não orienta para a educação multicultural (MOREIRA; CANDAU, 2003). Para Teixeira e Bezerra (2007), os professores devem enfatizar as implicações culturais subentendidas em cada conhecimento, as quais se situam em determinado contexto. Além disso, destacam que diferentes abordagens pedagógicas devem ser adotadas, a fim de oferecer distintas oportunidades de discussão e compreensão para alunos com diferentes culturas, ritmos e dificuldades de aprendizagem.

A esse respeito, a oficina de multiletramentos proposta neste estudo pode ser considerada propícia para trabalhos com diversos conteúdos na perspectiva multicultural, uma vez que valorizou os conhecimentos e letramentos dos alunos, adquiridos em sua imersão na cultura digital. Com esse modelo de oficina, os alunos tiveram a oportunidade de se expressar e produzir materiais a partir de diferentes recursos digitais, interagindo com 0 conteúdo disciplinar de forma autônoma e criativa.

Quanto ao gênero meme, utilizado na segunda fase da oficina como meio de representação da adolescência, pode-se dizer que os alunos trabalharam com uma linguagem que já faz parte de seu cotidiano, que favorece a criatividade e autoria - tendo, por isso, potencial pedagógico segundo apontam diversos estudos (KNOBEL; LANKSHEAR, 2005; COELHO, 2017; OLIVEIRA; PORTO; ALVES, 2019). É um gênero digital que dialoga com a perspectiva do multiculturalismo, por articular distintas culturas, devido à sua intertextualidade. Conforme Oliveira, Porto e Alves (2019), interpretar um meme implica entender a sua lógica, o que se configura como uma atividade de aprendizagem, uma vez que sua elaboração, a partir da 
sobreposição de diferentes signos, exige do leitor a capacidade de situá-los perante um contexto próprio, por meio do exercício da leitura e tradução. Os autores destacam que "cada meme em seu contexto, replicado em larga escala, ou não, possui uma carga ideológica e discursiva que permite amplas leituras e visões diferentes" (p.6) e, dessa maneira, possibilita um espaço multirreferencial de aprendizagem, um espaço plural, no qual os indivíduos constroem pontes interculturais e reinventam seus cotidianos.

Embora o meme seja considerado uma linguagem informal, ele pode apresentar questões sérias, preconceitos, ideologias e críticas e, por isso, gerar distintos debates que, na escola, podem contribuir tanto para o aprendizado de conteúdo quanto para a formação crítica. Assim, as discussões suscitadas por questões trazidas em memes possuem potencial para romper com as dicotomias, que silenciam ou inferiorizam as demais culturas. Além disso, a interpretação e elaboração de memes podem favorecer a ampliação de habilidades de leitura e escrita, indo além das dimensões gramatical e textual que a escola costuma privilegiar (FERREIRA, VILHARTA-NEDER, COE, 2019).

Neste estudo, os memes produzidos pelos alunos revelaram indícios preliminares de que esses jovens têm percebido sua adolescência não apenas do ponto de vista biológico, mas também social, cultural, familiar e escolar, demonstrando reações de frustração, dilema, resistência, baixa autoestima e satisfação. Nesse sentido, é importante que haja interfaces entre os conteúdos curriculares e as questões socioculturais que permeiam a adolescência. É preciso construir práticas pedagógicas dialógicas, inclusivas e multidimensionais, pois a adolescência se mostra atravessada por essas várias dimensões, as quais se entrelaçam e apresentam uma dinâmica própria que não condiz com um currículo monocultural e dicotomizado em disciplinas isoladas.

Ressalta-se que a visão da multiculturalidade no currículo não se limita a tolerar a diversidade, mas consiste no reconhecimento dos valores culturais do outro, em prol do respeito ao diferente e do seu direito de se manifestar (COSSETIN, 2017). Isso significa que o currículo e as práticas escolares devam valorizar e reconhecer todas as culturas, que abranjam os sujeitos da comunidade escolar, sem hierarquização de seus conhecimentos e valores. 
Para Candau (2011), os sujeitos são atravessados por múltiplos contextos, assim como várias questões de raça, gênero, classe social, entre outras, o que mostra o quão complexo e dinâmico é o ser humano.

Nessa concepção, é importante romper com o pensamento dicotômico e homogêneo, que deslegitima aquele que está fora do padrão, e construir novas práticas pedagógicas, uma vez que a percepção das realidades pelos sujeitos se estabelece em um "processo contínuo de construção-desconstrução-construção" (CANDAU, 2011, p.249).

\section{CONSIDERAÇÕES FINAIS}

A GDV permitiu identificar o caráter reativo dos memes, produzidos pelos alunos, ao revelar as perspectivas de sua adolescência por meio de personagens de filmes e desenhos ou seriados que fazem parte de suas culturas juvenis. Contextos de cotidianos vieram à tona, mostrando influência de diferentes dimensões (social, cultural, familiar, biológica) enquanto se constituem como adolescentes e alunos. Ainda assim, se mostram capazes de articular modos semióticos para construir significados, pensar, criticar, ser autores e autônomos ao criar suas próprias representações sobre sua adolescência. Determinadas representações caracterizam aspectos predominantemente negativos sobre essa fase de vida para tais jovens, o que precisa ser levado em consideração pela escola, uma vez que essas questões podem influenciar no desempenho escolar (GROLLI; WAGNER; DALBOSCO, 2017).

Para Candau (2008), reconhecer a monoculturalidade da escola é um primeiro passo para superar a lacuna entre as vivências socioculturais dos jovens e a cultura escolar. Urge estruturar um currículo multicultural, o qual demande novas posturas de docentes, integração de saberes, novos norteadores curriculares e de avaliação, entre outros (MOREIRA, CANDAU, 2003). Assim, as práticas pedagógicas precisam ser criticamente ressignificadas para atender os jovens do século XXI, o que requer um currículo dinâmico, que congregue a diversidade de adolescências, com respeito e equidade, acolhendo o repertório cultural de seus alunos, sem 
hierarquias. Considera-se que as representações de adolescência dos alunos podem promover implicações pedagógicas nesse sentido, promovendo-se a articulação do conteúdo curricular às questões, como no caso das que se mostraram tão importantes a esses alunos em seus memes.

Além disso, a linguagem memética também pode prover implicações pedagógicas quando utilizada para explorar a intertextualidade, o cotidiano, o caráter dialógico e horizontal entre os pares, promovendo um pensamento crítico incorporado ao currículo, de maneira que o jovem possa reconhecer-se e ser reconhecido pela comunidade escolar e a sociedade. Assim, em meio a um prestígio social do domínio da escrita, novas formas de representação e de narrativas digitais estão se formando e rompendo com a lógica do grafocentrismo, ainda vigente nas escolas (KRESS, 2003; ROCHA, 2007).

Considera-se que a proposta de oficina deste estudo dialoga com o multiculturalismo, ao explorar a produção de memes, uma linguagem popular na internet, principalmente entre jovens. Tanto imagens como textos escritos foram utilizados a partir do universo sociocultural desses alunos, o que possibilitou a manifestação de diferentes culturas e contextos sociais e se alinha à Semiótica Social (HODGE, KRESS, 1988). Contudo, é importante destacar que os dados coletados por meio dos memes são sucintos e, por isso, constituem-se como indícios da adolescência desse grupo de jovens. Entrevistas ou questionários podem ser utilizados junto aos memes para aprofundar a compreensão sobre como esses jovens veem sua adolescência.

A escola precisa promover uma educação inclusiva e democrática, percebendo que seus alunos são adolescentes com distintas experiências e conhecimentos socioculturais. Assim, a apropriação pedagógica de uma linguagem cultural como o meme, capaz de trazer para a prática questões e realidades que estão no dia a dia dos alunos, pode ser um caminho.

\section{REFERÊNCIAS}

ALMEIDA, M. B. T.; VALENTE, J. A. Integração currículo e tecnologias e a produção de narrativas digitais. Currículo sem Fronteiras, v. 12, n. 3, p. 57- 82, 2012. 
ALMEIDA, M. E. B. Currículo e narrativas digitais em tempos de ubiquidade: criação e integração entre contextos de aprendizagem. Revista de Educação Pública, v. 25, n. 59/2, p. 526-546, 2016.

BARTHES, R. Introdução à análise estrutural da narrativa. In: BARTHES, R. et al. Análise estrutural da narrativa, Petrópolis: Vozes, 7 ed., 1971, p. 19-62. BLACKMORE, S. The meme machine. Oxford: Oxford University Press, 1999.

BOCK, A. M. B. A adolescência como construção social: estudo sobre livros destinados a pais e educadores. Psicologia Escolar e Educacional (Impr.), v. 11 , n. 1, p. 63-76, 2007.

CAMACHO, L. M. Y. A invisibilidade da juventude na vida escolar. Perspectiva, v. 22, n. 2, p. 325-343, 2004.

CANDAU, V. M. F. Direitos humanos, educação e interculturalidade: as tensões entre igualdade e diferença. Revista Brasileira de Educação, v. 13, n. 37, p. 45-56, 2008.

CANDAU, V. M. F. Diferenças Culturais, Cotidiano Escolar e Práticas Pedagógicas. Currículo sem Fronteiras, v. 11, n. 2, p. 240- 255, 2011.

CANEN, A. O Multiculturalismo e seus dilemas: implicações na educação.

Comunicação e Política, v. 25, n. 2, p. 91-107, 2007.

COELHO, C. Que histórias os memes podem nos contar? Pedagogias culturais e currículo. Revista Brasileira de Pesquisa (Auto)biográfica, v. 2, n. 6 p. 615-628, 2017.

COPE, B.; KALANTZIS, M. Multiliteracies: New literacies, new learning. Pedagogies: An International Journal, v. 4, n. 3, p. 164-195, 2009.

CORSI, A. M.; LIMA, E. F. Práticas Pedagógicas no Ensino Fundamental na Perspectiva do Culturalismo Crítico, Currículo sem Fronteiras, v. 10, n. 2, p. 158-182, 2010.

COSSETIN, V. L. F. Suportar ou reconhecer: a dupla face do conceito de tolerância e o papel mediador da escola. Pro-Posições, v. 28, p.132-146, 2017.

COUTINHO, L. G. Adolescência e Errância: Destinos do Laço Social Contemporâneo. Rio de Janeiro: Nau, 2009.

DAHL, R.; ALLEN, N.; WILBRECHT, L.; SULEIMAN, A. B. Importance of investing in adolescence from a developmental science perspective. Nature, v. 554, p. 441-450, 2018.

DAYRELL, J. A escola "faz" as juventudes? Reflexões em torno da socialização juvenil. Educação \& Sociedade, v. 28, n. 100, p. 1105-1128, 2007. 
DAWKINS, Richard. O gene egoísta. São Paulo: EDUSP, 1976.

FERRARI, P. A web somos nós. In: FERRARI, P. Hipertexto hipermídia: as novas ferramentas da comunicação digital. São Paulo: Contexto, p. 7-12, 2007.

FERREIRA, H. M.; VILLARTA-NEDER, M. A.; COE, G. S. C. Memes em sala de aula: possibilidades para a leitura das múltiplas semioses. Revista Periferia, v. 11 , n. 1 , p. 114-139, 2019.

FURLANETTO, M. F.; LAUERMANN, F.; COSTA, C. B.; MARIN, A. H. Educação sexual em escolas brasileiras: revisão sistemática da literatura. Cadernos de Pesquisa, v. 48, n. 168, p.550-571, 2018.

GROLLI, V.; WAGNER, M. F.; DALBOSCO, S. N. P. Sintomas Depressivos e de Ansiedade em Adolescentes do Ensino Médio. Revista de Psicologia da IMED, v. 9, n. 1, p. 87-103, 2017.

HODGE, B.; KRESS, G. Social Semiotics. London: Polity Press, 1988.

JENKINS, H. Cultura da Convergência. São Paulo: Aleph, 2. ed., 2009.

JEWIT, C.; OYAMA, R. Visual meaning: A social semiotic approach. In: VAN LEEUWEN, T. JEWIT, C. (orgs.). Handbook of visual analysis. London: Sage, 2001, p. 134-157.

KENSKI, V. M. Educação e tecnologias: o novo ritmo da informação. Campinas: Ed. Papirus, 2012.

KNOBEL, M.; LANKSHEAR, C. Memes and affinities: Cultural replication and literacy education. Miami: NRC, 2005. p. 1-22.

KRESS, G. Literacy in the new media age. New York: Routledge, 2003.

KRESS, G.; VAN LEEUWEN, T. Reading images: the grammar of visual design. New York: Routledge, 2006.

KRESS, G. Multimodality: A social semiotic approach to contemporary communication. New York: Routledge, 2010.

LE BOTERF,G. Pesquisa participante: propostas e reflexões metodológicas. In: BRANDÃO, C. R. (org.) Repensando a pesquisa participante. São Paulo: Brasiliense, p. 51-81, 1999.

MANOVICH, L. El lenguage de los nuevos medios de comunicación: la imagen en la era digital. Barcelona: Paidós, 2005.

MARTINS, C. R.; PELEGRINI, A.; MATHEUS, S. C.; PETROSKI, E. L. Insatisfação com a imagem corporal e relação com estado nutricional, adiposidade corporal 
e sintomas de anorexia e bulimia em adolescentes. Revista de Psiquiatria do Rio Grande do Sul, v. 32, n. 1, p. 19-23. 2010.

MILNER, R. The world made meme: Discourse and identity in participatory media. 2012. 316p.Tese (Doutorado em Filosofia) - Universidade do Kansas, Kansas/EUA, 2012.

MINAYO, M. C. de S. Ciência, técnica e arte: o desafio da pesquisa social. In: MINAYO, M. C. S.; DESLANDES, S. F.; NETO, O. C. (org.). Pesquisa social: teoria, método e criatividade. Petrópolis: Vozes, 21. ed., p. 9-29, 2002.

MOREIRA, A. F. B.; CANDAU, V. M. Educação escolar e cultura(s): construindo caminhos. Revista Brasileira de Educação, n. 23, p. 156-168, 2003.

NISSENBAUM, A.; SHIFMAN, L. Internet memes as contested cultural capital: the case of 4chan's/b/board. New Media \& Society, v. 19, n. 4, p. 483-501, 2017.

OLIVEIRA, K. E. J.; PORTO, C. M.; ALVES, A. L. Memes de redes sociais digitais enquanto objetos de aprendizagem na Cibercultura: da viralização à educação. Acta Scientiarum Education, v. 41, e42469, p. 1-11, 2019.

PÁTARO, C. S. O.; MORUZZI, A. B. Culturas juvenis e cumículo: valorização dos sujeitos jovens no trabalho escolar. Revista Teias, Rio de Janeiro, v. 12, n. 26, p. 61-81, set./dez. 2011.

ROCHA, H. Repensando o ensino da língua portuguesa: uma abordagem multimodal. In: VIEIRA, J. A; ROCHA, H.; MAROUN, C. R. G. B.; FERRAZ, J. A. (org.). Reflexões sobre a língua portuguesa: uma abordagem multimodal. Petrópolis: Vozes, p. 35-76, 2007.

ROJO, R. Pedagogia dos multiletramentos: Diversidade cultural de linguagens na escola. In: ROJO, R.; MOURA, E. (Orgs). Multiletramentos na Escola. São Paulo: Parábola Editorial, p. 11-32, 2012.

TEIXEIRA, C. R.; BEZERRA, R. Dal B. Escolas, cumículo e cultura(s): a construção do processo educativo na perspectiva da multiculturalidade. Dialogia, v. 6, p. 55-63, 2007.

VASCONCELOS, M. S. Ousar brincar. In: ARANTES, V. A. (Org.). Humor e Alegria na Educação. São Paulo: Summus, p. 57-74, 2006.

WORTHMAN, C.; TRANG, K. Dynamics of body time, social time and life history at adolescence. Nature, 554(7693), p.451-457, 2018.

ZACHARIAS, V. R. C. Letramento digital: desafios e possibilidades para o ensino. In: COSCARELLI, C. V. (org.). Tecnologias para aprender. São Paulo: Parábola Editorial, p. 15-26, 2016. 
Aprovado em: 03 de julho de 2020

Publicado em: 30 de julho de 2020

(c) $\underset{\mathrm{Br}}{\mathrm{Br}}(\mathrm{Sc}$ 